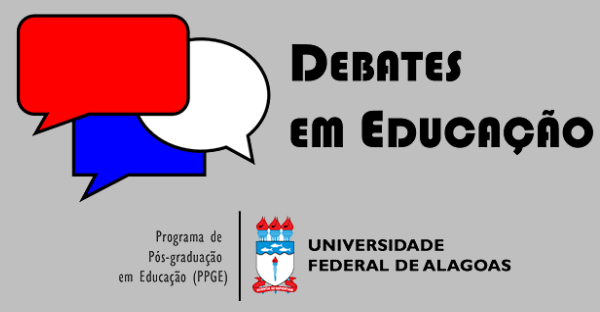

ISSN Eletrônico 2175-6600

Vol. 13 | N. 31 I Jan./Abr. | 2021

Maria do Socorro Ferreira Ramos (0) iD

Universidade do Estado do Rio Grande do Norte (UERN) mariasframos@gmail.com

Otávio Paulino Lavor

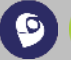

Universidade Federal Rural do Semi-Árido

(UFERSA)

otavio.lavor@ufersa.edu.br

\section{EDUCAÇÃO FINANCEIRA ATRAVÉS DA METODOLOGIA STEAM: INOVAÇÕES EDUCACIONAIS NO ENSINO SUPERIOR}

\section{RESUMO}

A educação financeira possibilita, dentre outras competências, que as pessoas desenvolvam o consumo consciente e possam gerir melhor suas finanças. Considerando que os universitários estão na iminência do exercício profissional e do contato mais ativo com finanças pessoais, faz-se necessária a conscientização dos riscos e da necessidade de planejamento financeiro. Nesse sentido, uma intervenção foi realizada com uma amostra de estudantes de cursos de engenharia. Para tanto, realizou-se um minicurso através da metodologia STEAM que integra as áreas de ciências, tecnologia, engenharia, artes e matemática. $\mathrm{Na}$ ocasião, foram discutidos diversos conceitos da educação financeira a partir de um filme, bem como seus impactos para o empreendedorismo em engenharia. Ademais, foram diferenciados os tipos de juros e realizadas simulações nos aplicativos "Minhas Finanças" e "Calculadora do Cidadão". Os participantes responderam a uma avaliação gamificada e demonstraram compreender a relevância da educação financeira para o futuro pessoal e profissional. Verificou-se que o método STEAM foi eficiente para o alcance dos objetivos propostos.

Palavras-chave: BNCC. Tecnologia. Planejamento financeiro.

\section{FINANCIAL EDUCATION THROUGH STEAM METHODOLOGY: EDUCATIONAL INNOVATIONS IN HIGHER EDUCATION}

\begin{abstract}
Financial education enables, among other skills, that people develop conscious consumption and can better manage their finances. Considering that university students are on the verge of professional practice and more active contact with personal finances, awareness of the risks and the need for financial planning is necessary. In this sense, an intervention was carried out with a sample of students from engineering courses. To this end, a short course was conducted through the STEAM methodology that integrates the areas of science, technology, engineering, arts and mathematics. At the time, several concepts of financial education from a film were discussed, as well as their impacts on engineering entrepreneurship. In addition, the types of interest were differentiated and simulations were carried out in the Minhas Finanças and Calculadora do Cidadão applications. Participants responded to a gamified assessment and demonstrated to understand the relevance of financial education for the personal and professional future. It was found that the STEAM method was efficient in achieving the desired objectives.
\end{abstract}

Keywords: BNCC. Technology. Financial planning.

Submetido em: 30/12/2020

Aceito em: 15/04/2021

Publicado em: 26/06/2021 


\section{INTRODUÇÃO}

A educação financeira envolve conceitos do universo das finanças, através de processos que percorrem temas como consciência, controle de gastos e investimentos com vistas ao bem-estar pessoal e social responsável. É através destes processos que as pessoas criam estímulos à conscientização em relação às finanças e podem tomar decisões melhores e conscientes para sua vida (RAMOS; MOURA; LAVOR, 2020).

Segundo Rosa e Orey (2016), uma finalidade importante da educação financeira é proporcionar um processo de ensino e aprendizagem, auxiliando as pessoas para que exerçam a cidadania de forma responsável na resolução de problemas. Já Dias e Olgin (2020) argumentam que esse tema possibilita o estabelecimento de conexões entre os conteúdos matemáticos e questões da vida pessoal, profissional e social.

Compreendendo a relevância da educação financeira para a formação do ser, pode-se questionar o interesse pelo assunto, bem como o processo para ensinar e aprender. Vieira e Pessoa (2020) colocam essa temática como política pública e dizem que há um empenho em difundir uma cultura de educação financeira capaz de orientar quanto ao uso do dinheiro. No caso do Brasil, o ensino desta temática se tornou obrigatório com a nova Base Nacional Comum Curricular (BNCC) publicada em 2018.

Segundo a BNCC, é crescente a importância da educação financeira e da compreensão do sistema monetário, imprescindíveis para uma inserção crítica e consciente no mundo atual (BRASIL, 2018). Então, desenvolver a educação financeira possibilitará que o indivíduo seja consciente e crítico dos problemas e soluções, sendo capaz de controlar suas despesas e receitas.

Considerando que trabalhar este tema proporcionará um ambiente favorável ao consumo consciente, indaga-se como a educação financeira pode ser dialogada em sala de aula. O uso da etnomatemática enseja que "a análise financeira pode proporcionar a identificação de escolhas adequadas, além de promover um consumo consciente". (CHIAPPETTA e SILVA, 2019, p. 97).

Cordeiro, Maia e Silva (2019) utilizam histórias em quadrinhos no ciclo de alfabetização, apresentando propostas de atividades que estimulam operações envolvendo dinheiro, bem como levantam discussões sobre a importância de estabelecer prioridades de gastos e pesquisa de preços quando se deseja um produto. No ensino superior, Silva et. al. (2019) realizaram um minicurso com o objetivo de promover a aprendizagem da organização financeira e perceberam que os participantes obtiveram o 
entendimento sobre administração do dinheiro, passando a analisar criticamente os aspectos de negociações.

Cordeiro, Maia e Silva (2019) dizem que a educação financeira pode ser abordada de diversas formas, a depender do público que se deseja atingir. Considerando o público como sendo estudantes do ensino superior na área de engenharias e buscando uma metodologia interdisciplinar, propõe-se um minicurso em educação financeira na perspectiva da metodologia STEAM (Science, Technology, Engineering, Arts and Mathematics) que busca integrar as áreas de ciências, tecnologia, engenharia, artes e matemática como indica o acrógrafo.

\section{REVISÃO BIBLIOGRÁFICA}

\subsection{Educação financeira}

A educação financeira é um tema que abrange conhecimentos pelos quais as pessoas podem compreender, planejar e controlar as suas finanças. Segundo a Organização para a Cooperação e Desenvolvimento Econômico (OCDE), tem-se que:

[...] educação financeira é o processo mediante o qual os indivíduos e as sociedades melhoram a sua compreensão em relação aos conceitos e produtos financeiros, de maneira que, com informação, formação e orientação, possam desenvolver os valores e as competências necessários para se tornarem mais conscientes das oportunidades e riscos neles envolvidos e, então, poderem fazer escolhas bem informadas, saber onde procurar ajuda e adotar outras ações que melhorem o seu bem-estar. Assim, podem contribuir de modo mais consistente para a formação de indivíduos e sociedades responsáveis, comprometidos com o futuro (OCDE, 2005, p. 4).

Um indivíduo que desenvolve conhecimento nas finanças pessoais está apto ao planejamento financeiro pessoal com competências para reconhecer oportunidades e tomar decisões quanto à aplicação do dinheiro. Para Vieira e Pessoa (2020), esse processo é lento, pois necessita de avaliações, revisões periódicas e políticas permanentes que promovam uma conscientização efetiva para melhorar a compreensão das pessoas sobre as próprias finanças.

A fim de atender às recomendações da OCDE, através do Decreto n ${ }^{\circ} 397$ de 22 de dezembro de 2010, foi implementada a Estratégia Nacional de Educação Financeira (ENEF) na qual era previsto, dentre outras diretrizes, a atuação por meio de informação, formação e orientação. Este decreto foi revogado pelo Decreto $n^{\circ} 10.393$ de 9 de junho de 2020 que instituiu a nova ENEF e o Fórum Brasileiro de Educação Financeira (FBEF). 
Pelo novo decreto, a ENEF tem como finalidade promover a educação financeira, securitária, previdenciária e fiscal no país, enquanto que o FBEF tem, dentre outras, a competência de compartilhar as informações sobre estas ações para identificar as oportunidades de articulação.

Quanto à implementação da educação financeira na escola, a OCDE (2009) esclarece que:

[...] a educação financeira nas escolas deve ser desenvolvida preferencialmente por meio de um planejamento e programa coerente, ter recursos adequados, envolver avaliação rigorosa, ser fornecido o mais cedo possível, ser incluído no currículo escolar como um elemento obrigatório (disciplina autônoma ou incorporado em outras disciplinas), e se concentrar no desenvolvimento de conhecimentos financeiros, habilidades, atitudes, bem como comportamentos financeiros responsáveis. Os professores também devem ser engajados, bem treinados e apoiados (OCDE, 2009, p. 4).

A nova Base Nacional Comum Curricular (BNCC) prevê na unidade temática Números que sejam discutidos assuntos como impostos, rentabilidade e liquidez de um investimento, favorecendo um estudo que envolve questões de trabalho, consumo e dinheiro e desenvolvendo a habilidade de associação de porcentagens para solucionar e elaborar problemas em contextos de educação financeira (BRASIL, 2018). Assim, a educação financeira fica compreendida de forma interdisciplinar sendo oferecida desde meados do ensino fundamental.

Embora a educação financeira esteja prevista na BNCC, deve-se considerar que o público anterior a estas previsões e que já passou pelo nível fundamental e médio, pode não ter obtido acesso a esse conhecimento. Ferreira e Castro (2020) buscam identificar o nível de conhecimento de alunos de graduação sobre gestão financeira pessoal e constatam que menos de 10\% obtiveram através da escola, mostrando que há carência de abordagem em finanças, sem ainda oferecer disciplinas que auxiliam no desenvolvimento de jovens e adultos educados financeiramente.

Quando da realização de um estudo sobre educação financeira envolvendo os alunos de uma instituição de ensino superior, Silva et. al. (2019) concluíram que os alunos, mesmo em semestres distintos, afirmaram ter conhecimento sobre as diversas opções de investimento, entretanto não demonstraram assertividade em suas escolhas, compreendendo que o tempo de curso não é fator determinante. Vidal, Silva e Valdevino (2020) identificam a percepção de graduandos em Ciências Contábeis sobre educação financeira e concluem que apenas $10,92 \%$ se sentem seguros, possuindo conhecimentos bastante amplos sobre finanças. 
No ensino médio, Araújo et. al. (2020) abordam a importância da educação financeira no terceiro ano em uma escola profissionalizante e notam a importância dessa temática para o desenvolvimento profissional auxiliando na formação, bem como destacam a maior facilidade para a atuação no mercado para quem adquire esse conhecimento. Ramos, Moura e Lavor (2020) utilizam uma sequência didática para discutir a educação financeira em uma turma do ensino médio e constatam que os discentes reconhecem a necessidade de planejamento para gestão de recursos. Assim, percebe-se que o tema é amplo e precisa ser trabalhado de forma efetiva em diversos níveis de ensino, pois até nos cursos em que se espera maior conscientização, a eficácia quanto a assuntos relacionados à educação financeira tem apresentado baixos níveis.

\subsection{Método STEAM}

O método STEAM conta com (se vale da, proporciona, recorre a) a integração das áreas de ciências, tecnologia, engenharia, artes e matemática e segundo Bacich e Holanda (2020) vem do termo STEM (Science, Technology, Engineering and Mathematics) que surgiu nos Estados Unidos com a junção das iniciais das áreas de ciências, tecnologias, engenharia e matemática e depois o termo ganhou (recebeu, foi acrescido da) a letra $A$ de artes.

Acrescentando as artes, verificaram que a imaginação e os processos de criação foram intensificados. Verificaram também que as artes se tornaram importantes culturalmente, comunicativamente e facilitadoras da aprendizagem das outras áreas envolvidas no sistema. O cuidado agora é para que no STEAM as artes não virem mero trabalho de ilustração (BARBOSA, 2017, p. 13).

O acréscimo de artes à metodologia tornara a proposta mais interdisciplinar, fortalecendo uma aproximação entre áreas distintas e para Machado e Girotto Júnior (2019), essa adição amplia o alcance da metodologia e desperta interesse e motivação dos alunos para a área. Estes autores afirmam, ainda, que o STEAM é interdisciplinar, uma vez que o desenvolvimento parte da integração entre áreas do conhecimento, contemplando habilidades práticas com a engenharia e a tecnologia, bem como habilidades teóricas como ciências e matemática.

A metodologia STEAM pode ser vista como uma alternativa metodológica para enfrentar desafios dos processos de ensino e aprendizagem. Neste sentido,

[...] a educação STEAM pode contribuir para lidar com os desafios contemporâneos, ajudando a pensar uma educação que, sem abandonar a excelência acadêmica, também desenvolva competências importantes, como a 
criatividade, o pensamento crítico, a comunicação e a colaboração (BAClCH; HOLANDA, 2020, p. 2).

Lorenzin, Assumpção e Rabello (2016) esclarecem que, nesta metodologia, os temas são explorados de forma investigativa, partindo da proposição de um problema, podendo se expandir para a realização de projetos, pautados na aprendizagem ativa. Os autores ainda pontuam que no STEAM as cinco áreas envolvem processos criativos, em que as informações são compartilhadas e exploradas em novos caminhos para perceber e pensar a criatividade. Lorenzin e Bizerra (2016) analisam as concepções iniciais de professores e revelam o conceito do STEAM como estratégia de ensino com base no conhecimento integrado para estratégia de aprendizagem com foco no aluno e permite aos professores ressignificarem sua prática.

Como exemplo de aplicação do STEAM, Lorenzin, Assumpção e Rabello (2016) abordam o conceito de energia e suas transformações, desafiando os alunos a construírem uma máquina mecânica que representasse uma metáfora de um processo físico, químico, biológico ou artístico. Para os autores, os produtos e os conceitos produzidos concretizaram a possibilidade da abordagem interdisciplinar por projetos do STEAM, para o ensino dos conceitos de energia e suas transformações.

Hardoim et. al. (2019), discutiram através do STEAM, a superação de algumas dificuldades relativas à educação científica inclusiva, contribuindo para o exercício do ensino de Biologia. Os autores afirmam que, com esta metodologia, os estudantes trabalham de forma integrada e utilizam a interdisciplinaridade para apropriação do conhecimento de forma ativa.

Viana, Araújo e Cavalcante (2018) fazem uma análise do livro "Esporte de Aventura" e trabalham diversas disciplinas numa perspectiva interdisciplinar, atendendo a proposta da metodologia STEAM. As autoras destacam que a conexão entre várias disciplinas é mais significativa que a fragmentação dos assuntos.

Como pode ser visto, a metodologia STEAM favorece um diálogo multidisciplinar, sendo uma alternativa para o ensino de diversos conhecimentos, dentro os quais, os relacionados à educação financeira, foco desta investigação na qual estudantes de ensino superior são o público alvo. 


\section{METODOLOGIA}

Um minicurso de educação financeira foi realizado de forma remota através da plataforma Google Meet durante o mês de julho de 2020, em uma universidade localizada na região do alto oeste potiguar. Sabendo-se que o campus da universidade possui 1460 discentes ativos e considerando uma amostra com confiabilidade de 90\%, o minicurso obteve a participação de 65 (sessenta e cinco) discentes. Tal amostra foi calculada a partir da Equação (1) a seguir:

$$
\text { Tamanho da amostra }=\frac{z^{2} p(1-p) N}{z^{2} p(1-p)+(N-1) \theta^{2}}
$$

em que $Z$ é o valor tabelado na distribuição normal de probabilidade que depende do grau de confiança, $p$ é a estimativa da proporção, e é o erro e $N$ é o tamanho da população. (FONSECA, MARTINS, 2016).

$\mathrm{Na}$ realização do minicurso de educação financeira, a metodologia STEAM proporcionou a integração das áreas de ciências, tecnologia, engenharia, artes e matemática, ao oportunizar a execução de atividades multidisciplinares. Antecipadamente, foi enviado aos inscritos o filme "Os Delírios de Consumo de Becky Bloom" para que pudessem refletir sobre os problemas enfrentados pela protagonista que, em suma, trata-se de uma jovem que compra compulsivamente e que por consequência contrai diversas dívidas com utilização de cartões de crédito.

Para integrar as ciências, foi apresentado o contexto histórico da educação financeira, bem como a definição e pressupostos legais para o ensino e aprendizagem, demonstrando a evolução, a relevância da temática no campo científico e sua inserção na BNCC. Neste momento, trechos do filme foram retomados para fazer conexão entre os conteúdos e a arte. Quanto à tecnologia, os aplicativos "Minhas Finanças" e "Calculadora do Cidadão" foram utilizados para demonstrar um controle de gastos e perspectivas de investimentos, respectivamente. A Figura 1 mostra a interface destes aplicativos. 
Figura 1: Interface dos aplicativos - a) "Minhas Finanças”; b) “Calculadora do Cidadão”.

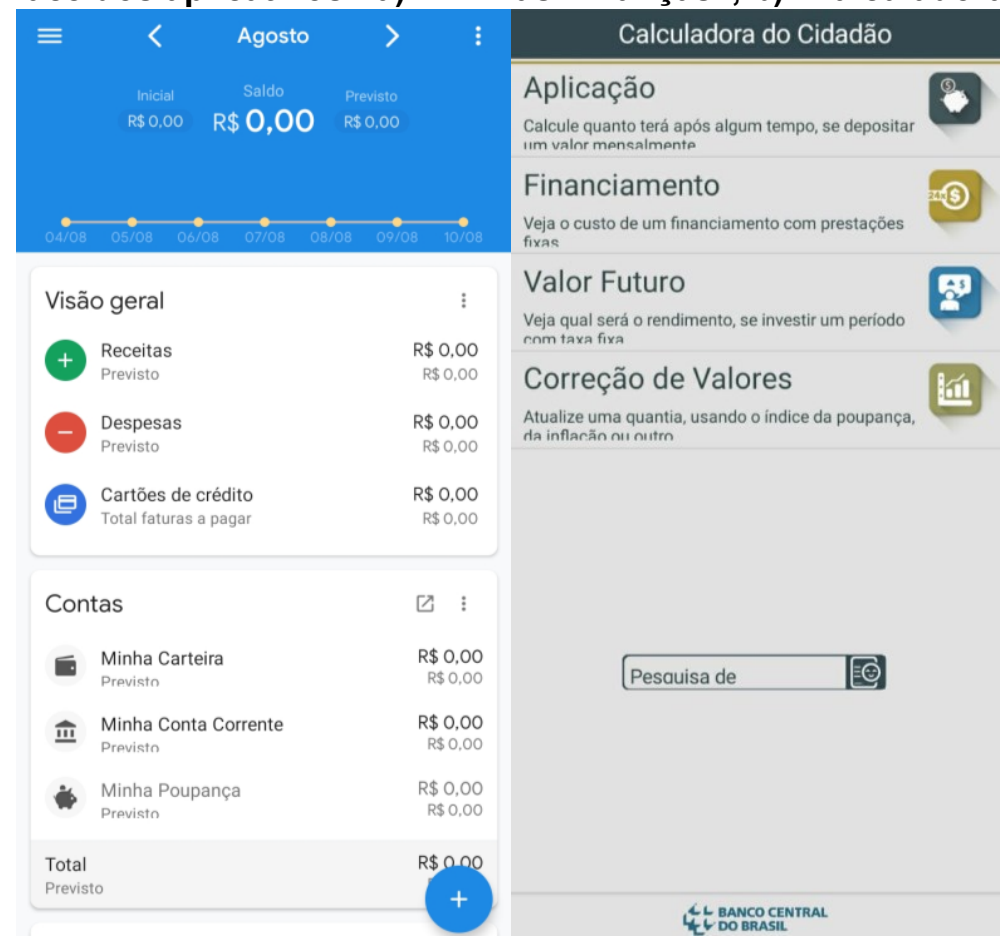

a)

b)

Como o público alvo da pesquisa é constituído por discentes dos cursos de engenharias, o empreendedorismo nesta área foi fonte de motivação para integrar e despertar o interesse pelo assunto. Dessa forma, foram mostrados detalhes financeiros para adquirir bens de capital para o exercício da profissão. No campo da matemática, a educação financeira foi abordada pelo ponto de vista das taxas de juros e financiamentos aplicados no mercado, bem como dadas orientações para cálculos rápidos de aplicações financeiras. A Tabela 1 mostra um resumo da sequência de atividades realizadas.

Tabela 1: Etapas da sequência de atividades.

\begin{tabular}{lll}
\hline Atividade & Área & Recurso \\
\hline Apresentação de definições e contexto histórico & Ciências & Slides \\
Apresentação de controle de gastos e investimentos & Tecnologia & Aplicativos \\
Discussão sobre empreendedorismo na profissão & Engenharia & Aplicações \\
Reflexão diante das ações da protagonista & Artes & Filme \\
Discussão sobre taxa de juros e rendimentos & Matemática & Simulações
\end{tabular}

Para avaliar os objetivos de aprendizagem, após o minicurso, um questionário foi utilizado de forma gamificada. A gamificação é uma metodologia que utiliza os elementos de um jogo para fins de aprendizagem. Nesse sentido, o formulário utilizou questões 
objetivas com pontuações e cada participante verificava sua pontuação logo após o preenchimento no Google Forms. A Tabela 2 traz um resumo das questões apresentadas na avaliação.

Tabela 2: Questões da avaliação.

\begin{tabular}{cll}
\hline Questão & \multicolumn{1}{c}{ Assunto } & Pontuação \\
\hline 1 & Conhecimento prévio de planejamento financeiro & 0 pontos \\
2 & Gestão financeira & 1 ponto \\
3 & Lições a partir do filme & 1 ponto \\
4 & Planejamento financeiro no aplicativo & 1 ponto \\
5 & Reserva de emergência & 1 ponto \\
6 & Planejamento pessoal & 1 ponto \\
7 & Contribuição dos aplicativos para a & 0 pontos \\
& aprendizagem & \\
9 & Fatores de aprendizagem & 0 pontos \\
9 & Educação financeira como conteúdo curricular & 0 pontos \\
\hline
\end{tabular}

As questões listadas na Tabela 2 buscaram identificar o conhecimento adquirido sobre educação financeira, bem como verificar a satisfação dos participantes quanto à metodologia utilizada no minicurso. As questões que não possuem pontuação verificam percepções e características pessoais sem caráter avaliativo. A análise das respostas irá fornecer uma reflexão sobre a viabilidade do STEAM em atividades de educação financeira.

\section{RESULTADOS}

Durante a realização do minicurso de forma remota, foram apresentados os conteúdos de educação financeira, tratando sobre consumo consciente e consumismo, segurança financeira, investimento, reserva de emergência, bem como planejamento financeiro. A Figura 2 mostra um dos momentos de apresentação. 
Figura 2: Momento em que se discute Planejamento Financeiro.

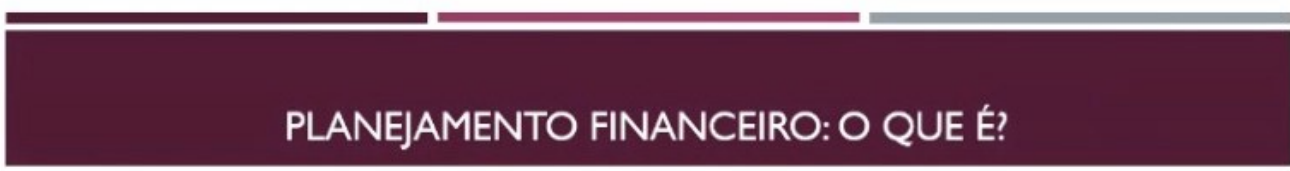

- Logo após as análises anteriores é possivel planejar e realizar outras etapas da gestão.

- Consumo planejado e consciente! compreensão dos hábitos de consumo (consumo por impulso, identificar as causas)

- Reserva de emergência: preparado para as adversidades! É composta por recursos investidos de forma ultra conservadora e bastante líquida, ou seja, baixissimo risco e fácil acesso. É a facilidade de transformar o ativo financeiro em dinheiro. Como calcular?

- Reserva de oportunidade: preparado para enxergar oportunidades. Ou encontrar terreno fértil para produzir frutos.

- Se possível, poupar para investir.
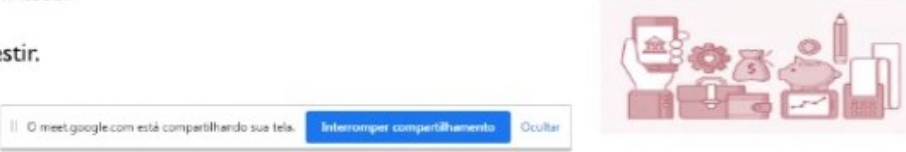

Neste momento, foi percebido que o público fazia uma relação entre as definições e as atividades pessoais e profissionais que um indivíduo pode executar de forma consciente. Os comentários e indagações mostraram a interação entre os conceitos e a prática diária no exercício de uma profissão.

A retomada do filme "Os Delírios de Consumo de Becky Bloom" foi realizada para explicar o consumismo e integrar a arte à aprendizagem. Através do cinema, é mostrado artisticamente: o fascínio da criança com o "cartão mágico"; a emoção de ter uma compra aprovada; a constatação da ilusão e dos malefícios provocados pelo consumismo; o processo de educação financeira e superação de dificuldades da personagem. A Figura 3 mostra um dos momentos de retomada.

Figura 3: Momento de retomada do filme.

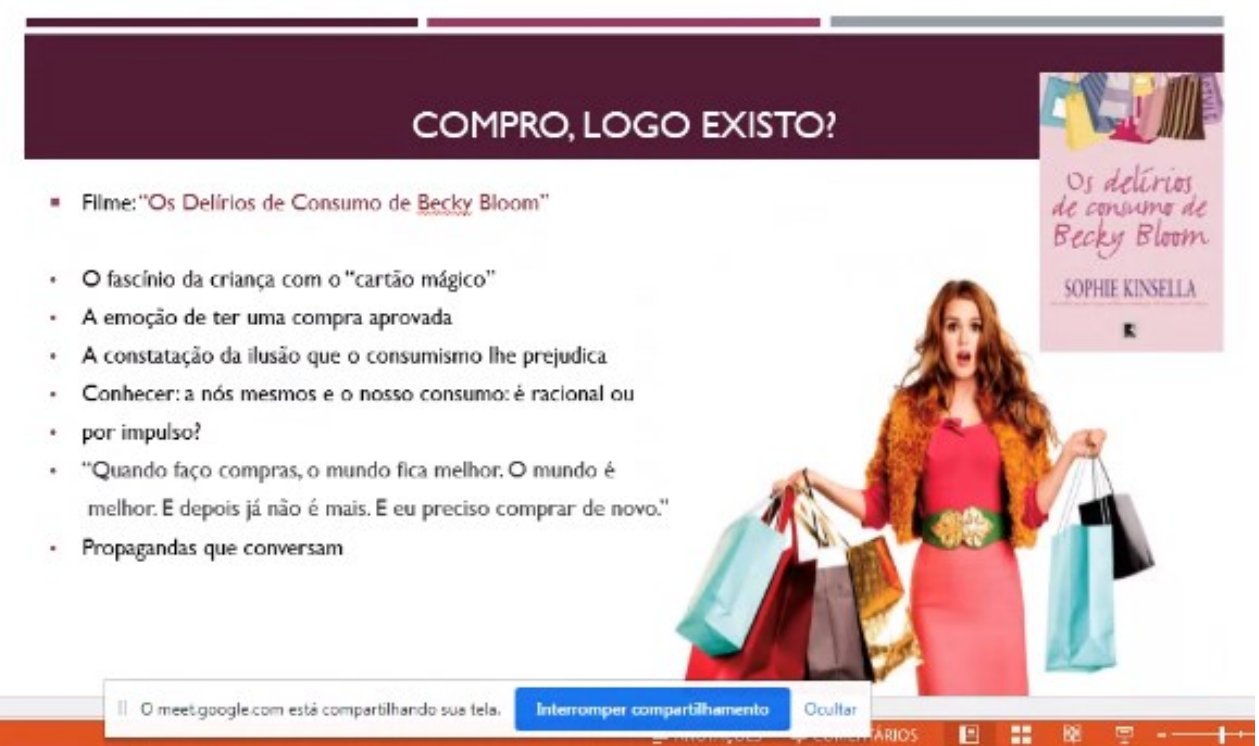


Este foi um dos momentos em que se questionava sobre o autoconhecimento em relação ao consumo, bem como o papel do marketing no processo de educação financeira. Uma vez conhecidos os conceitos para a educação financeira, o aplicativo "Minhas Finanças" foi utilizado como ferramenta para controle de gastos. A Figura 4 demonstra o aplicativo trabalhado com a turma.

Figura 4: Utilização do aplicativo "Minhas Finanças".

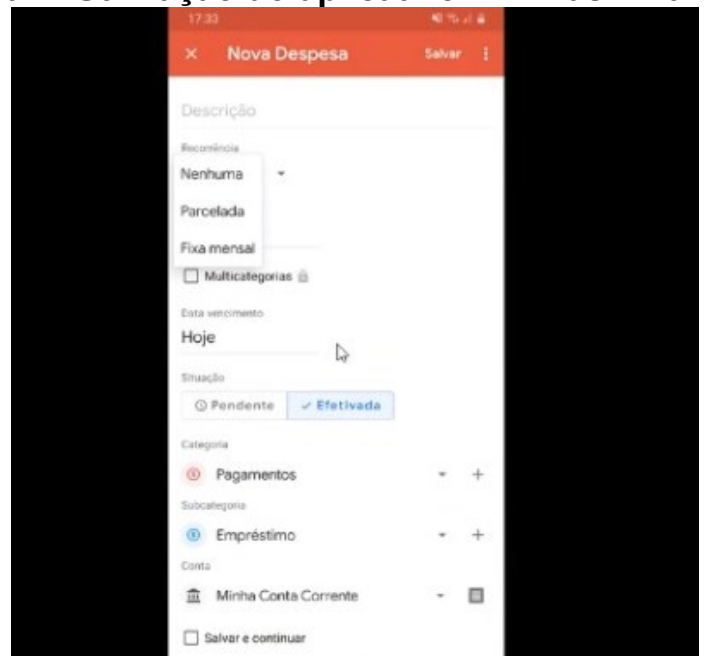

No campo da Engenharia, foi discutido o empreendedorismo e a busca de organização financeira pessoal e empresarial nas mais diversas possibilidades e necessidades destas carreiras profissionais. Dessa forma, buscou-se conduzir o aluno à reflexão sobre quais ações no presente podem garantir uma organização das condições mínimas de trabalho no futuro para o desempenho de sua profissão. Um destes momentos trabalhados na turma pode ser visto na Figura 5. 
Figura 5: Empreendedorismo na engenharia.

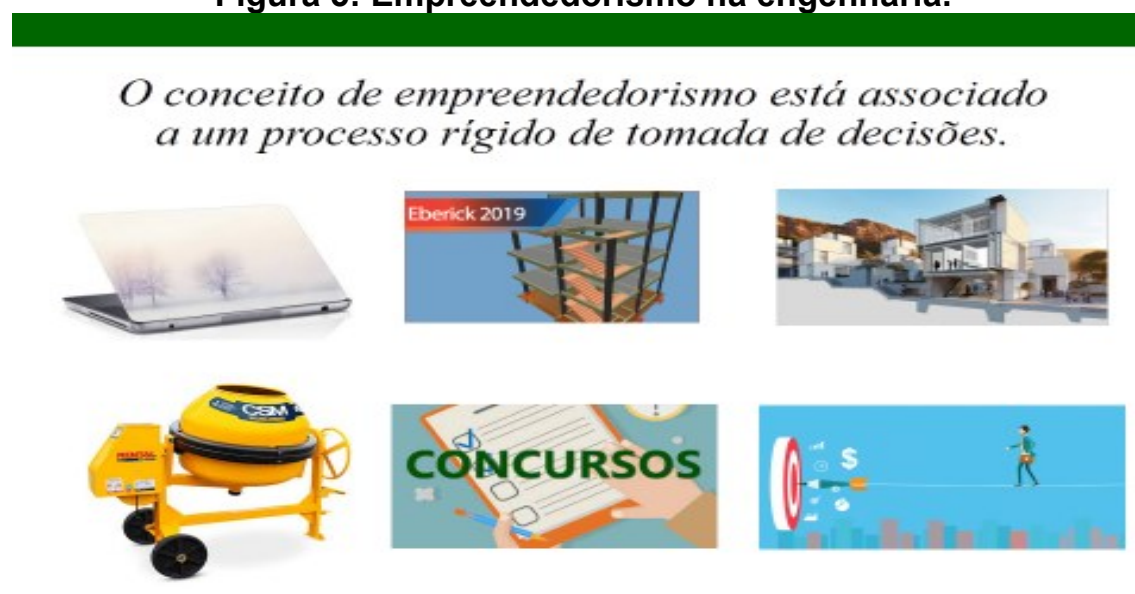

Em todos os momentos, a matemática foi apresentada para explicar as taxas e os conceitos envolvidos nos aplicativos, bem como discutidos os juros aplicados no mercado. A Figura 6 mostra um momento em que o aplicativo "Calculadora do Cidadão" é utilizado.

Figura 6: Utilização do aplicativo "Calculadora do Cidadão".

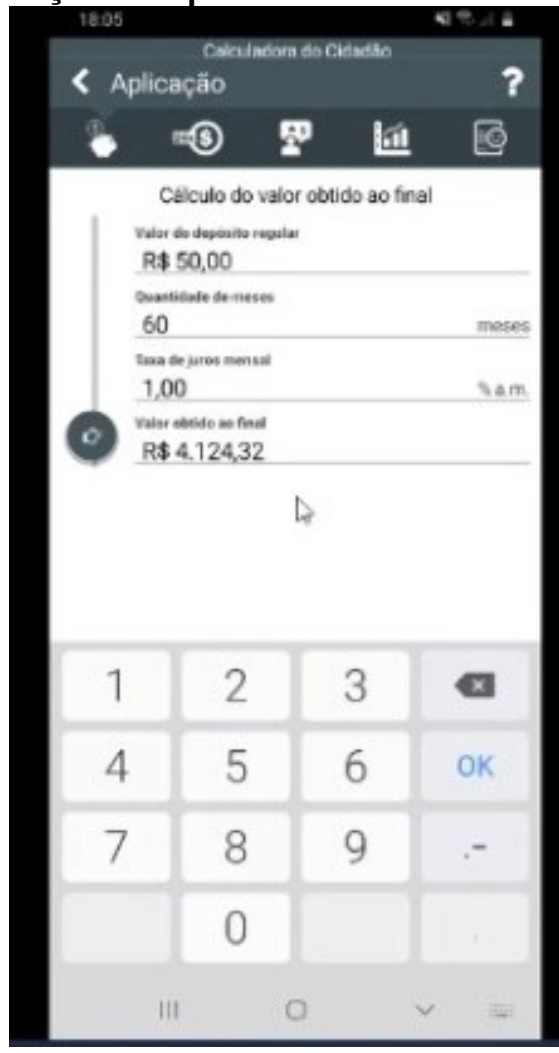

$\mathrm{Na}$ discussão sobre taxas de juros foram explicadas aquelas envolvidas em financiamentos e investimentos. Nesse momento, foram simuladas diversas situações práticas no aplicativo e foram destacados os tipos de empréstimos que possuem maiores 
e menores taxas, bem como a rentabilidade de um investimento em função do risco para o cliente.

Durante todo o minicurso, foram percebidas as interações entre os alunos e os ministrantes. Para verificar o alcance dos objetivos almejados, a avaliação foi de forma gamificada através do Google Forms. A seguir, podem-se conferir os resultados da avaliação.

O planejamento financeiro é um processo que ajuda as pessoas a organizarem a vida financeira pessoal ou familiar, por meio da elaboração de estratégias, a fim de atingirem seus objetivos. Nesse sentido, a primeira questão buscou identificar o conhecimento prévio do público, em que foram apresentadas três alternativas: a) não refleti sobre o tema; b) não refleti sobre o tema, mas percebo a importância de estudar melhor o assunto, afim de preparar-me para a gestão financeira; c) não refleti sobre o tema e ainda não percebi a importância de estudar melhor o assunto afim de preparar-me para a gestão financeira. As respostas mostram que 69,5\% responderam o item a), enquanto que $30,5 \%$ assinalaram a alternativa b) e nenhum dos discentes marcou a alternativa c).

Os participantes demonstraram através desta questão, bem como no decorrer dos diálogos no minicurso, que a educação financeira é relevante para lidar com o dinheiro no futuro. Essa percepção vem concordar com Araújo et. al. (2020), em que se evidencia a importância da temática e os impactos positivos gerados.

A segunda questão buscou compreender o conhecimento geral sobre gestão financeira e $84,6 \%$ assinalaram corretamente que gestão financeira é um processo dinâmico e contínuo e que, mesmo depois da estabilidade econômica, faz-se, ainda, necessário planejar. Nesse ponto, ressalta-se que a falta de uma boa gestão financeira pode levar ao saldo devedor crescente ou deixar as economias em um investimento medíocre por diversos anos.

A terceira questão buscou identificar a lição de educação financeira despertada pelo filme "Os Delírios de Consumo de Becky Bloom" nos alunos. Verificou-se que 61,5\% afirmaram que a falta de gestão e planejamento favorece situações de vulnerabilidade como o uso inconsciente do cartão de crédito. Já, 38,5 \% afirmaram como lição, que se devem evitar decisões de compra precipitadas, sob a influência do efeito manada, compreendendo a alta probabilidade de prejuízo nos negócios que não podem esperar por um período de reflexão ou de pesquisa de preço. Esses conhecimentos adquiridos podem ser associados à intensidade criada nos processos de assimilação devido ao acréscimo de artes na metodologia, como aponta Barbosa (2017). 
A quarta questão trouxe uma situação hipotética em que foi informado o salário líquido de um determinado profissional, bem como suas despesas com aluguel e compra parcelada de móveis em cartão de crédito. Então, foi pedido o cadastro das informações no aplicativo "Minhas Finanças" e o saldo deste profissional. Observando as respostas enviadas, $81,5 \%$ dos participantes registraram corretamente as informações e apresentaram o saldo. Este resultado mostra que o recurso tecnológico pode ser uma ferramenta auxiliar no controle de gastos e no processo de ensino e aprendizagem de educação financeira, visto que o aplicativo pode ser acessado sem recursos de internet e atualizado no momento das ações de receita ou despesa, evitando, portanto, a inconsistência de dados por diversos motivos como, por exemplo, o esquecimento do registro.

Na quinta questão, buscou-se verificar se os participantes tiveram apropriação do conhecimento de reserva de emergência e sessenta e quatro, dentre os sessenta e cinco participantes, afirmaram corretamente que é o recurso destinado para atender às situações extraordinárias como imprevisto, desemprego, crise ou outra despesa não planejada. Além disso, a reserva de emergência pode ser composta por recursos investidos de forma conservadora e bastante líquida, ou seja, de baixíssimo risco e fácil acesso ou retomada.

Em relação ao planejamento financeiro pessoal, tem-se que este é um assunto amplo e requer estudo aprofundado, mas não necessariamente complexo. Não refletir sobre isso, entretanto, pode representar um saldo negativo não apenas nas contas, mas também nos planos de vida. Sendo assim, a sexta questão identifica se os conhecimentos sobre planejamento financeiro foram adquiridos e $83,1 \%$ afirmaram que, para alcançarmos metas financeiras, a longo prazo, precisamos poupar uma parcela da renda. Tão relevante quanto poupar, é considerar o tempo como aliado no processo com proteção para que não seja atingido pela inflação e rentabilidade enquanto aguarda sua destinação.

Ainda foi abordado em uma das alternativas dessa questão, um assunto pertinente para o planejamento pessoal a longo prazo: a aposentadoria. Destaca-se que trabalhar a vida inteira e não pensar em uma previdência complementar é deixar por vezes apenas a cargo da previdência social um estágio do ciclo vital onde a fragilidade de diversas situações já será determinante.

Quando perguntado na sétima questão, se os aplicativos contribuíram para a aprendizagem de educação financeira, apenas um discente informou não ter sido muito relevante. A oitava questão buscou coletar informações sobre os fatores que conduziram 
à aprendizagem da temática, sendo que mais de uma opção era possível de ser assinalada dentre as seguintes alternativas: a) tecnologia; b) slides e textos; c) exposição oral. O fator tecnologia foi assinalado por $86,2 \%$, enquanto que os recursos de slides e textos foram assinalados por $61,5 \%$ e a exposição oral foi assinalada por $66,2 \%$. Diante dessas respostas, pode-se verificar que a tecnologia é considerada pelos discentes como um fator determinante para a aprendizagem, fato já percebido na questão anterior.

$\mathrm{Na}$ nona questão, foi perguntado se a educação financeira deveria ser tratada como um conteúdo na grade curricular do curso. Dos 65 discentes, 64 afirmaram que deveria ser integrado ao currículo como forma de preparar o aluno para cuidar bem dos recursos financeiros frutos do trabalho, independentemente da profissão que venha a ser escolhida. A Tabela 3 mostra um resumo das pontuações obtidas pelos participantes.

Tabela 3: Pontuações da avaliação.

\begin{tabular}{cc}
\hline Pontuação & Quantidade de participantes \\
\hline 0 & 0 \\
1 & 0 \\
2 & 2 \\
3 & 13 \\
4 & 27 \\
5 & 23
\end{tabular}

Pela Tabela 3, pode-se verificar que vinte e três participantes têm nota máxima, apenas dois obtiveram pontuação menor que 3 e que a média da turma é 4,1 em uma escala de zero a cinco. Como foi tomada uma amostra com nível de confiabilidade de $90 \%$, pode-se inferir que a população de discentes teria esta média, caso o minicurso fosse direcionado a todos, o que coloca o STEAM como uma metodologia a ser refletida e aplicada.

Estes resultados contribuem com Hardoim et. al. (2019), quanto à integração pela interdisciplinaridade provocada pelo STEAM. Foi percebido que, ao trabalhar a educação financeira levando em consideração diversas áreas do conhecimento, os participantes foram interativos, demonstrando motivação para a aprendizagem.

\section{CONCLUSÃO}

O ensino de educação financeira se tornou obrigatório segundo a BNCC e objetiva estimular a formação de indivíduos críticos, cientes e preparados para administrar as suas 
finanças de maneira eficaz. A obrigatoriedade fica prevista no ensino fundamental, no entanto, o tema é relevante para qualquer idade e pesquisas apontam que diversos estudantes de outros níveis de ensino não tiveram contato com o assunto ou ainda não obtiveram consciência financeira.

Neste sentido, este trabalho buscou desenvolver a educação financeira na perspectiva do método STEAM através de um minicurso sobre educação financeira. Tal experiência contou com um público de sessenta e cinco estudantes matriculados em cursos de engenharias, em uma amostra com nível de confiança de noventa por cento. $\mathrm{Na}$ área de ciências, foi explorado o contexto histórico e, principalmente, os conceitos de planejamento financeiro e reserva de emergência. Na área tecnológica, foram explorados os aplicativos "Minhas Finanças" e "Calculadora do Cidadão" para reflexão de como os recursos tecnológicos podem contribuir com o controle e cálculos financeiros.

$\mathrm{Na}$ área de artes foi disponibilizado o filme "Os Delírios de Consumo de Becky Bloom" com a visualização de casos práticos de descontrole financeiro e as dificuldades decorrentes dele. Na matemática, foram tratados os tipos de juros, bem como o cálculo de porcentagens e a análise gráfica de custos e investimentos, quanto ao risco e à rentabilidade.

Os resultados mostram que os estudantes compreenderam a educação financeira como fator determinante para o sucesso financeiro, demonstrando domínios em relação à gestão financeira e compreendendo que a falta de consumo consciente pode levar a situações indesejadas.

Destaca-se também que a maioria passa a compreender a dinâmica dos investimentos de longo prazo, reconhecendo que é necessário poupar uma parcela da renda para atingir um objetivo determinado e que o tempo é tão importante quanto o montante aplicado, pois caminha junto com os juros. Os estudantes entenderam que a educação financeira é relevante para a vida profissional e deveria ser integrada ao currículo do curso.

Diante do exposto, pode-se afirmar que o minicurso apresentado com o método STEAM trouxe resultados satisfatórios para o ensino e aprendizagem de educação financeira. Então, espera-se que os fatos narrados contribuam para outros momentos a favor do consumo consciente, bem como estimule novas ações para informar e discutir o tema de educação financeira. Além disso, como trabalhos futuros sugere-se a intervenção desta temática em níveis fundamental e médio e a aplicação do método STEAM na apropriação de outros conhecimentos. 


\section{REFERÊNCIAS}

ARAÚJO, D., SILVA, A., MENEZES, B., MENDES, D. A importância da educação financeira: um estudo no ensino profissionalizante. Revista de Graduação USP, v. 4, n. 1, p. 125-137, 2020. Disponível em:

<http://www.periodicos.usp.br/gradmais/article/view/156398/162220>. Acesso em: 08 set. 2020.

BACICH, L.; HOLANDA, L. (org.). STEAM em sala de aula: a aprendizagem baseada em projetos integrando conhecimentos na educação básica. Porto Alegre: Penso, 2020.

BARBOSA, A. M. O dilema das Artes no Ensino Médio no Brasil. Pós: Revista do Programa de Pós-graduação em Artes da EBA/UFMG. v.7, n.13, p. 9-17, 2017. Disponível em: <https://periodicos.ufmg.br/index.php/revistapos/article/view/15702/pdf >. Acesso em: 09 jun. 2020.

BRASIL. Estratégia Nacional de Educação Financeira, 2010. Disponível em: <http://www.planalto.gov.br/ccivil_03/_Ato2007-2010/2010/Decreto/D7397.htm > Acesso em: 08 de abril de 2020.

BRASIL. Base Nacional Comum Curricular. Ministério da Educação. Brasília: MEC, 2018. Disponível em:

<http://basenacionalcomum.mec.gov.br/images/BNCC_EI_EF_110518_versaofinal_site.p df>. Acesso em: 07 set. 2020.

BRASIL. Institui a nova Estratégia Nacional de Educação Financeira - ENEF e o Fórum Brasileiro de Educação Financeira - FBEF, 2020. Disponível em: <http://www.planalto.gov.br/ccivil_03/_Ato2019-2022/2020/Decreto/D10393.htm\#art10> Acesso em: 07 set. 2020.

CHIAPPETTA, S. K. S.; SILVA, J. R. Uma proposta para o ensino de educação financeira embasada na etnomatemática: consumo consciente a partir do contexto do orçamento financeiro. TANGRAM - Revista de Educação Matemática, v. 2, n. 1, p. 79-101, 2019. Disponível em: <http://ojs.ufgd.edu.br/index.php/tangram/article/view/8848/4838>. Acesso em: 09 set. 2020.

CORDEIRO, N. J. N.; MAIA, M. G. B.; SILVA, C. B. P. O uso de histórias em quadrinhos para o ensino de educação financeira no ciclo de alfabetização. TANGRAM - Revista de Educação Matemática, v. 2, n. 1, p. 03-20, jan. 2019. Disponível em: <http://ojs.ufgd.edu.br/index.php/tangram/article/view/8668/4819>. Acesso em: 09 set. 2020.

DELÍRIOS de consumo de Becky Bloom. Direção: P. J. Hogan. Elenco: Isla Fisher, Hugh Dancy, Krysten Ritter, Joan Cusack e outros, DVD color. 104 min. (2009).

DIAS, C. R.; OLGIN, C. A. Educação matemática crítica: uma experiência com o tema educação financeira. Revista Eletrônica de Educação Matemática, v. 15, p. 1-18, 2020. Disponível em: <https://periodicos.ufsc.br/index.php/revemat/article/view/19811322.2020.e70007>. Acesso em: 08 set. 2020. 
OCDE. Recommendation on Principles and Good Practices for Financial Education and Awareness, 2005. Disponível em: <http://www.oecd.org/finance/financialeducation/35108560.pdf>. Acesso em: 07 set. 2020.

OCDE. Brazilian International Conference on Financial Education, 15-16 December 2009, Rio de Janeiro, Brazil, 2009. Disponível em: <https://www.oecd.org/daf/fin/financial-education/44506555.pdf>. Acesso em: 08 set. 2020.

FERREIRA, J. B.; CASTRO, I.M. Educação financeira: nível de conhecimentos dos alunos de uma instituição de ensino superior. Revista de Administração e Negócios da Amazônia, v. 12, n. 1, p. 134-156, 2020. Disponível em: <https://www.periodicos.unir.br/index.php/rara/article/view/4574/3327>. Acesso em: 29 dez. 2020.

FONSECA, J. S.; MARTINS, G.A. Curso de Estatística. 6 ed. São Paulo: Atlas,2016. HARDOIM, E. L.; HARDOIM, T. F. L.; NAKAMURA, C. R.; HARDOIM, A. H. L. Educação científica inclusiva: experiências interdisciplinares possíveis para o ensino de biologia e ciências naturais empregando o método STEAM. LATIN AMERICAN JOURNAL OF SCIENCE EDUCATION, v. 6, n. 1, p.1-9, 2019. Disponível em: <http://www.lajse.org/may19/2019_12056.pdf>. Acesso em: 03 set. 2020.

LORENZIN, M. P.; ASSUMPÇÃO, C. M.; RABELLO, M. Metáforas mecânicas: uma proposta STEAM para o ensino de ciências. In: 6 Congresso Pesquisa do Ensino educação e tecnologia: revisitando a sala de aula. 2016. p. 1-14. Disponível em: <http://www1.sinprosp.org.br/conpe6/revendo/assets/-re---81--metaforas_-mecanicas_steam.pdf.pdf>. Acesso em: 03 set. 2020.

LORENZIN, M. P.; BIZERRA, A. F. Compreendendo as concepções de professores sobre o STEAM e as suas transformações na construção de um currículo globatizador para o ensino médio. Revista da SBEnBio, n. 9, p. 3662-3673, 2016. Disponível em:

<https://sbenbio.org.br/wp-content/uploads/edicoes/revista_sbenbio_n9.pdf>. Acesso em: 09 set. 2020.

MACHADO, E. S.; GIROTTO JÚNIOR, G. Interdisciplinaridade na investigação dos princípios do STEM/STEAM education: definições, perspectivas, possibilidades e contribuições para o ensino de química. Scientia Naturalis, v. 1, n. 2, p. 43-57, 2019. Disponível em: <https://revistas.ufac.br/index.php/SciNat/article/view/2492>. Acesso em: 03 set. 2020.

RAMOS, M. S. F.; MOURA, P. S.; LAVOR, O. P. Educação financeira: sequência didática com o aplicativo Minhas Economias. Revista de Investigação e Divulgação em Educação Matemática, v. 4, n.1, p. 1-19, 2020. Disponível em:

<https://periodicos.ufjf.br/index.php/ridema/article/view/32047/21697>. Acesso em: 29 dez. 2020.

ROSA, M.; OREY, D. C. Encontros polissêmicos entre a educação financeira e a etnomatemática: um ensaio teórico. BOEM - Boletim online de Educação Matemática, v.4. n.7, p. 139-162, 2016. Disponível em:

<https://revistas.udesc.br/index.php/boem/article/view/8860>. Acesso em: 08 set. 2020. 
SILVA, F. T. A. S.; ARAÚJO, A. G. P.; MORAES, F. R. F.; ALVES, F. R. V. Educação Financeira para estudantes da Educação Superior. TANGRAM - Revista de Educação Matemática, v. 2, n. 3, p. 16-27, 2019. Disponível em:

<http://ojs.ufgd.edu.br/index.php/tangram/article/view/8988/5418>. Acesso em: 09 set. 2020.

SILVA, C. C.; RODRIGUES, M. P. S.; MOURA, J. A.; CASTRO, W. A. Educação financeira: um estudo envolvendo os alunos de uma instituição de ensino superior da cidade de Divinópolis em Minas Gerais. Research, Society and Development, v. 8, n. 8, p. 1-22, 2019. Disponível em: <https://rsdjournal.org/index.php/rsd/article/view/1177/968>. Acesso em 25 jun. 2020.

VIANA, D. L.; ARAUJO, C. S. O.; CAVALCANTE, D. S. Análise interdisciplinar das estórias do livro "esportes de aventura" numa perspectiva STEAM. REAMEC - Rede Amazônica de Educação em Ciências e Matemática, v. 6, n. 3, p. 105-117, 2018. Disponível em:

<https://periodicoscientificos.ufmt.br/ojs/index.php/reamec/article/view/7723>. Acesso em: 4 set. 2020.

VIDAL, Y. D. R. L.; SILVA, K. P.; VALDEVINO, R. Q. S. Percepção dos discentes de ciências contábeis sobre educação financeira. Revista Conhecimento Contábil, v. 10, n. 1, p. 80-95, 2020. Disponível em:

<http://natal.uern.br/periodicos/index.php/RCC/article/view/1925/1772>. Acesso em 08 set. 2020.

VIEIRA, G. S.; PESSOA, C. A. Educação financeira pelo mundo: como se organizam as estratégias nacionais?. Educação Matemática Pesquisa: Revista do Programa de Estudos Pós-Graduados em Educação Matemática, v. 22, n. 2, p. 658-688, 2020. Disponível em: <https://revistas.pucsp.br/emp/article/view/47580>. Acesso em: 08 set. 2020. 